\title{
Research on Knowledge Transfer Networks, Enterprise Relationship Networks and Innovation in Traditional Industrial Cluster
}

\author{
Min $\mathrm{LI}^{1,}$ a, Yan-ling SONG ${ }^{1}$, Zheng-qun $\mathrm{ZHAN}^{1,}$, , ${ }^{*}$ and Zi-ting $\mathrm{LI}^{1}$ \\ ${ }^{1}$ School of Economics and Commerce, South China University of Technology, P.R. \\ China, 510004

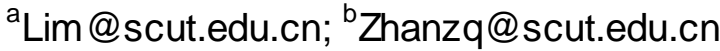 \\ ${ }^{*}$ Corresponding Author
}

Keywords: Knowledge transfer, Enterprise relationship networks, Innovation, Traditional industrial cluster.

\begin{abstract}
Knowledge transfer has significant impact on enterprises' innovation performance and in SME clusters various relationships between enterprises is the main channel of knowledge transfer. Knowledge and information transfer through enterprises' relationships and then promote the enterprises' innovation activities, which is the primary way of traditional industrial SMEs to obtain innovation in China. This research bases on the practices of Foshan lighting cluster and constructs the whole network of formal member enterprises of Foshan Lighting Association. The goal of this article is to demonstrate the structural characteristics of knowledge transfer networks and to examine mainly through which enterprise relationship that explicit and tacit knowledge transfer and to demonstrate how the location of enterprise within the knowledge transfer network plays a key role in the innovation performance. Findings are that explicit knowledge transfers not only by the weak market ties but also by the strong social ties while the transfer of tacit knowledge mainly depends on the social ties. Centrality in both explicit and tacit knowledge networks has significant positive impact on the product and process innovation, however, the structure hole has non-significant influence on innovation performance.
\end{abstract}

\section{Introduction}

As a network, cluster has many opportunities to achieve the knowledge transfer between enterprises by contacting with each other in different ways [1], and the knowledge can be divided into tacit and explicit knowledge. The acquisition, transfer and creation of knowledge are the important activities in the process of knowledge management. Knowledge transfer is the precondition and foundation of knowledge creation, effective knowledge transfer is critical for organizational process and output [2]. The relationship networks between enterprises can be used as an effective channel of knowledge transfer, in turn, affecting the enterprise innovation performance.

The research on knowledge transfer of industry cluster focused on exploring the factors affecting knowledge transfer. In recent years, there emerged a new dynamic by the two methods of the social network analysis and the complex network analysis. They mainly studied the problem of network position, strength of ties and the structure of network on the influence of knowledge transfer[3]. Under the social network perspective of knowledge transfer research mainly along the path — "network--knowledge transfer--innovation performance". 
The dependent variations of these researches mainly includes the extent of knowledge transfer and innovation performance. The construction of network depends on the specific relationship between the node. The methods of measuring the relationship mainly considers four aspects, including the length of time, frequency, proximity, reciprocity and trust[4]. Uzii (1996) put forward that relationships on the basis of the market are weak, and that based on social relations are strong [5].

The researches studied the correlation between structural attributes and knowledge transfer and innovation on the individual level and overall level. In the study of innovation as the dependent variable, the independent variables included not only structural attributes, also include resource attributes, for example, enterprise' capacity of absorptive knowledge and so on. Structural attribute of the most involved in the existing literature is network position, which are the centrality and the structure holes.Wastyn and Czarnitzki (2010) pointed that centrality can promote product innovation both in explicit and tacit knowledge transfer network, but this innovation has a stronger connection with explicit knowledge. At the same time, there is a stronger link between process innovations and internal knowledge[6].Centrality can promote process innovation. In the study about structural holes, Burt (1992) considered that the enterprise as structural holes have the advantages of maintaining and controlling information, because it can get close to others unconnected each other. Enterprise occupied structural holes has higher product innovation performance.

This study did the following work on the basis of the research of Cristobal Casanueva etc. (2013) [7]. First, to construct the whole network within cluster and to analysis the structure. Second, we studied what kind of relationship between enterprises is depended by the transfer of explicit and tacit knowledge. Thirdly, the impact of enterprises position within the explicit and tacit knowledge network on the innovation performance has been investigated. In addition, to a certain extent, the relationship between the owners can represent the relationship between enterprises within Foshan Lighting Cluster. Therefore, this study did not distinguish between business owner's networks and enterprise networks. They referred to as the enterprise networks generally.

\section{The Construction of Knowledge Transfer Network and Structure Analysis}

\section{Data Collection, Object of Study and Construction of Network}

The enterprise knowledge transfer network is a set of knowledge transfer relationship between each group. Enterprise is the "point" of network, relationship of knowledge transfer between enterprises is the "line". These points and lines construct the knowledge transfer network in cluster. With the support of Foshan Lighting Association, we selected all 36 paid-up member enterprises of it to construct the whole network. During January to April 2015, we visited the 36 enterprises one by one with staffs of the Association to collect data through the 30 to 60 minutes semi-structured interview and a mentoring questionnaire for each entrepreneur.

Table 1. The basic data of the enterprise

\begin{tabular}{l|l|l|l|l}
\hline Enterprise characteristics & \multicolumn{5}{|l}{} \\
\hline Size $(X)$ & $X<20$ & $20 \leq X<300$ & $300 \leq X<1000$ & $X \geq 1000$ \\
\hline$\%$ & $5.55 \%$ & $66.67 \%$ & $25 \%$ & $2.78 \%$ \\
\hline $\operatorname{Age}(N)$ & $N<5$ & $5 \leq N<10$ & $10 \leq N<20$ & $N \geq 20$ \\
\hline$\%$ & $11.11 \%$ & $33.33 \%$ & $25 \%$ & $30.56 \%$ \\
\hline International & Yes & No & \\
\hline$\%$ & $91.67 \%$ & $8.33 \%$ & \\
\hline
\end{tabular}


The basic data of the enterprise (table1) shows that the number of employees of $66.67 \%$ enterprises are in the range of 20 to 300 .Cluster presents typical pyramid structure. In addition, the age of $33.33 \%$ enterprises is in the range of 5 to 10 , the age of $30.56 \%$ enterprises is more than 20 years. This reflects that the cluster belongs to the mature traditional industry cluster with history. Enterprises over the age of 20 have experienced the process of transformation and upgrading from the hardware processing, the traditional lighting manufacturing to power and LED manufacturing. According to the data about enterprise internationalization, there are only three enterprises without foreign trade, which explains that the cluster has been in global value chain. Therefore, this cluster is the typical traditional industrial clusters that is mainly SMEs in our country.

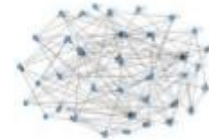

Fig.1. Explicit

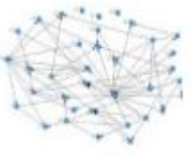

Fig.2. Tacit

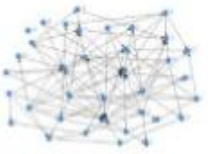

Fig.3. Business

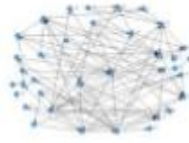

Fig.4.Cooperation

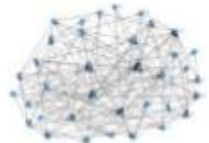

Fig.5. Trust

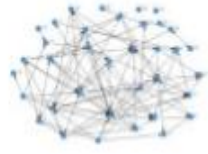

Fig.6.Friendship

Then we dealt with the collected data by Netdraw, and get knowledge transfer networks - explicit knowledge transfer network(Fig.1) and tacit knowledge transfer network(Fig.2).Results show that the explicit network contains 77 ties and tacit knowledge transfers by 39 ties. Every enterprise has more than one tie at least, which reflects that the knowledge transfer within a cluster is common.

\section{Structure Analysis}

Table 2 lists the main structure index of knowledge transfer networks. The density of explicit and tacit knowledge network is $12.5 \%$ and $6.3 \%$ respectively, indicated that both knowledge networks are not tight. The size of average neighborhood is 4.389 and 2.194 respectively, which shows that each enterprise transfers knowledge with at least two enterprises in average in both knowledge network. Results point that the out-degree centrality of both knowledge networks are higher than in-degree centrality, which declares that main knowledge senders of two networks are concentrated. Besides, in-degree centrality of the explicit knowledge network is double the tacit one, which reflects that the number of transferring knowledge is more in explicit knowledge network and knowledge of each node accepted is more uniform. The number of isolated nodes and components proved this point. Isolated nodes of both networks are 0 and 3 respectively, which shows that explicit knowledge transfer is common. Components of both networks are 8 and 31.We can see from this result that the number of group in the explicit network is more .

Table 2. Structural characteristics of the networks under analys is

\begin{tabular}{l|l|l|l|l|l|l}
\hline & $\begin{array}{l}\text { Density } \\
\%\end{array}$ & $\begin{array}{l}\text { Neighborhood } \\
\text { average size }\end{array}$ & $\begin{array}{l}\text { Degree (out degree } \\
\text { /in degree) } \%\end{array}$ & Betweenness & $\begin{array}{l}\text { Isolated } \\
\text { nodes }\end{array}$ & Components \\
\hline explicit & 12.5 & 4.389 & $31.184 / 28.245$ & 3.849 & 0 & 8 \\
\hline tacit & 6.3 & 2.194 & $31.755 / 14.122$ & 0.731 & 3 & 31 \\
\hline commercia 1 & 8.7 & 3.028 & $17.551 / 38.122$ & 3.035 & 1 & 22 \\
\hline cooperate* & 8.3 & 2.889 & $35.592 / 23.837$ & 2.01 & 0 & 22 \\
\hline trust & 15.9 & 5.556 & $39.510 / 48.327$ & 3.721 & 2 & 5 \\
\hline friends* & 9.6 & 3.361 & $22.449 / 31.265$ & 1.776 & 2 & 17 \\
\hline
\end{tabular}




\section{The Correlation Analysis}

\section{Market and Social Network Construction}

This study referred to the research methods of Cristóbal Casanueva,etc(2013)and studied all 6 kinds of relationship between enterprises from market to social relationship, they are business, subcontract, cooperation, trust, friendship and kinship. We obtain the data of all relationship by questionnaire, and draw four networks(Fig.3-6)without the kinship and subcontract. In order to facilitate discussion, we see business relationship and cooperation relationship as the market relationship, and trust relationship and friendship relations as the society relationship.

In accordance with the calculation of the four networks' structure indexes, we can draw the conclusion that: The standard deviation of nodes' degree centrality of business and cooperation are 10.932 and 12.401 respectively. Compared with the cooperate relationship network, ties in the business network is distributed uniformly. The node degrees of centrality standard deviation of trust and friendship networks is $16.227,11.703$ respectively. Compared with the trust relationship network, ties in the friendship network is distributed uniformly. Furthermore, table 2 shows that the overall density of four networks are $8.7 \%, 8.3 \%, 15.9 \%$ and $9.6 \%$ respectively, indicated that the trust relationship between enterprises within cluster is the most densest, and the rest two market networks are relatively loose, especially cooperation network.

In fact, the situation within Foshan Lighting cluster is more cooperation and less competition. The links of enterprises in the cluster are mainly business relationship. Enterprises are not only on the basis of "friendship" to develop business, they can also refer to traders 'price, quality, payment terms and other factors. And horizontal cooperation between enterprises is less. They rarely cooperated to buy equipment, purchase and share distribution channels. Figures 3 and 4 provided evidence. In addition, through the investigation and research, we knew that because of the cluster has a long history, the external competition is fierce, industry changed drastically, and industry associations is existed. The external constraint and self-discipline make enterprises try to establish a good image, improve product quality. Therefore, the overall level of trust between enterprises is higher, and it also formed dense trust network.

\section{MRQAP Analysis}

As is known to all, different enterprise relationships can transfer different knowledge (explicit or tacit). Combining the explicit knowledge network with tacit knowledge network, this study verifies that explicit and tacit knowledge transfer mainly through what kind of relationship (business, cooperation, trust and friendship) by MRQAP method. The results are as follows:

Model 2 about explicit knowledge network in table 3 shows that explicit knowledge transfer is significant with business and cooperate. This is consistent with the results of various empirical researches. The results of model 4 that joined the trust relationship and friendship on the basis of model 2 show that explicit knowledge is significant with 4 kinds of relationship, that is to say, both market and social relationship can promote the transfer of explicit knowledge. $\mathrm{R}^{2}$ had a big change that increased to 0.343 of model 4(including market and social relationship) from 0.235 of model 2 (only including market relationship), which indicates that when an enterprise owns the four kinds of relationship at the same time, trust has the biggest effect on explicit knowledge flows. The results show that explicit knowledge transfer is mainly 
through the enterprise social relations, namely weak ties. This can explain the fact that social relationship within Foshan Lighting cluster is particularly important. The fact is the phenomenon of more competition but less cooperation. Enterprise often use social relationship to connect new customers and access to information, such as by eating and talking with entrepreneurs to obtain information about the market, potential customers, sales channels. Through this informal form to achieve contract is a common phenomenon within the cluster. In such a cluster, compared with social relationship, the role of market relationship for the explicit knowledge transfer is weak relatively.

Table3. MRQAP results for explicit and tacit knowledge network

\begin{tabular}{|c|c|c|c|c|c|c|c|c|c|c|c|c|}
\hline & \multicolumn{2}{|c|}{$\begin{array}{lr}\text { The } & \text { whole } \\
\text { model/Explicit }\end{array} \mid$} & \multicolumn{4}{|c|}{ The continuous model/Explicit } & \multicolumn{2}{|c|}{$\begin{array}{l}\text { The whole } \\
\text { model/Tacit }\end{array}$} & \multicolumn{4}{|c|}{ The continuous model/Tacit } \\
\hline & St. & Sig. & Model 1 & Model 2 & Model 3 & Model 4 & St. & Sig. & Model 1 & Model 2 & Model 3 & Model 4 \\
\hline Business & 0.1 & 0.0004 & $0.377^{* * *}$ & $0.297^{* * *}$ & $0.141 * * *$ & $\begin{array}{l}* \\
*\end{array}$ & -0.036 & 0.14 & $0.235^{* * *}$ & $0.191^{* * *}$ & 0.037 & -0.036 \\
\hline Cooperate & 0.197 & 0.0002 & & $0.315^{* * *}$ & $0.234^{* * *}$ & $* 0.197^{* * *}$ & 0.0261 & 0.211 & & $0.171^{* * *}$ & $0.091^{* *}$ & 0.026 \\
\hline Trust & 0.315 & 0.0002 & & & $0.354 * * *$ & $* 0.315^{* * *}$ & 0.28 & 0.0002 & & & $0.349^{* * *}$ & $0.28^{* * *}$ \\
\hline Friendship & 0.171 & 0.0002 & & & & $0.171^{* * *}$ & 0.304 & 0.0002 & & & & $0.304^{* * *}$ \\
\hline $\mathrm{R}^{2}$ & 0.343 & 0 & 0.142 & 0.235 & 0.322 & 0.343 & 0.233 & 0 & 0.054 & 0.081 & 0.166 & 0.233 \\
\hline$\Delta \mathrm{R}^{2}$ & & & 0.142 & 0.093 & 0.087 & 0.021 & & & 0.054 & 0.027 & 0.085 & 0.067 \\
\hline
\end{tabular}

${ }^{*} p<0.05 ;{ }^{* *} p<0.01 ; * * * p<0.001$

In view of the tacit knowledge flow, model 4 about tacit knowledge network in table 3 shows that flowing of tacit knowledge is only positive significant with trust and friendship. By contrast, business and cooperation cannot explain the flowing of tacit knowledge well, and even coefficient of business is negative. Even if is not significant, it can reflect the reverse trend of the business with tacit knowledge transfer. In addition, $\mathrm{R}^{2}$ has two-fold increase from 0.081 of model 2 to 0.233 of model 4 . So, social relations (trust and friendship) is the main channel of tacit knowledge transfer.

In conclusion, within Foshan Lighting Cluster, the role of market relationship to promote knowledge transfer is smaller. In comparison, social relationship is the important channel of transferring knowledge .

\section{Network Position and Innovation Performance}

\section{Classification of Innovation and Data Collection}

There are mainly three kinds of methods on innovation performance. In the existing academic researches. Firstly, innovation is divided into product innovation and process innovation according to the content. Secondly, innovation is divided into radical innovation and incremental innovation according to the features. Thirdly, some researches use the overall index of innovation. This paper adopts the first classification method---product innovation and process innovation. The reason is that the radical innovation is disruptive and it does not match innovation reality existed in Foshan Lighting Cluster.

In collecting innovation data, according to the research of Zaheer \& Bell, we adopted the external evaluation method that combines enterprise mutual and expert evaluation. Enterprise mutual evaluation use 5-point Likert-type scale, the mean scores represent the levels of product innovation and process innovation for each firm. Three experts assessed the innovativeness of each firm on a 5-point Likert-type scale with a view to check the validity of 
the interviewees' (members of the network) innovation evaluations. The total scores of an enterprise given by three experts is innovation evaluation in expert aspect. Lastly, the final data of innovation is enterprise mutual plus expert evaluation.

\section{Network Positions and Innovation}

An Ordinary Least Squares (OLS) regression estimated the significance of network positions in relation to innovation. Regression results are as follows(table4,5):

Table 4. Analys is of network positions (product innovation)

\begin{tabular}{|c|c|c|c|c|c|c|c|c|c|}
\hline & \multirow[t]{2}{*}{ Variables } & \multicolumn{2}{|c|}{$\begin{array}{l}\text { Model } 0 \\
\text { (Controls only) }\end{array}$} & \multicolumn{2}{|c|}{$\begin{array}{l}\text { Model } 1 \text { (Adding } \\
\text { main effects) }\end{array}$} & \multicolumn{2}{|c|}{$\begin{array}{l}\text { Model } 2 \text { (Adding } \\
\text { main effects) }\end{array}$} & \multicolumn{2}{|c|}{$\begin{array}{l}\text { Model } 3 \\
\text { (Full model) }\end{array}$} \\
\hline & & B & & B & & B & & B & \\
\hline & Size & $0.010 * * *$ & & $0.008 * * *$ & & $0.006 * *$ & & $0.007 * * *$ & \\
\hline & Age & 0.042 & & 0.080 & & 0.070 & & 0.082 & \\
\hline & International & 2.248 & & 2.446 & & 1.038 & & 1.909 & \\
\hline \multirow{2}{*}{$\begin{array}{l}\text { Network of } \\
\text { tacit knowledge }\end{array}$} & Centrality & & & $0.266 * * *$ & & & & 0.206 & \\
\hline & Structural holes & & & 1.453 & & & & 0.785 & \\
\hline \multirow{4}{*}{$\begin{array}{l}\text { Network of } \\
\text { explicit knowledge }\end{array}$} & Centrality & & & & & $0.241 * *$ & & 0.086 & \\
\hline & Structural holes & & & & & -7.024 & & -3.795 & \\
\hline & Statistics & Value & Sign & Value & Sign & Value & Sign & Value & Sign \\
\hline & $\mathrm{R}^{2}$ & 0.486 & 0 & 0.649 & 0 & 0.621 & 0 & 0.632 & 0 \\
\hline
\end{tabular}

Table 5. Analysis of network positions (process innovation)

\begin{tabular}{|c|c|c|c|c|c|c|c|c|c|}
\hline & \multirow[t]{2}{*}{ Variables } & \multicolumn{2}{|c|}{$\begin{array}{l}\text { Model } 0 \\
\text { (Controls only) }\end{array}$} & \multicolumn{2}{|c|}{$\begin{array}{l}\text { Model } 1 \text { (Adding } \\
\text { main effects) }\end{array}$} & \multicolumn{2}{|c|}{$\begin{array}{l}\text { Model } 2 \text { (Adding } \\
\text { main effects) }\end{array}$} & \multicolumn{2}{|c|}{$\begin{array}{l}\text { Model } 3 \\
\text { (Full model) }\end{array}$} \\
\hline & & B & & B & & B & & B & \\
\hline & Size & $0.007 * * * *$ & & $0.006 * * *$ & & $0.004 * *$ & & $0.005^{* *}$ & \\
\hline & Age & -0.030 & & -0.005 & & -0.011 & & -0.005 & \\
\hline & International & 1.481 & & 1.582 & & 0.630 & & 1.083 & \\
\hline \multirow{2}{*}{$\begin{array}{l}\text { Network of } \\
\text { tacitt knowledge }\end{array}$} & Centrality & & & $0.182 * *$ & & & & 0.118 & \\
\hline & Structural holes & & & 0.822 & & & & 0.264 & \\
\hline \multirow{4}{*}{$\begin{array}{l}\text { Network of } \\
\text { explicit knowledge }\end{array}$} & Centrality & & & & & $0.169^{* *}$ & & 0.082 & \\
\hline & Structural holes & & & & & -4.696 & & -2.938 & \\
\hline & Statistics & Value & Sign & Value & Sign & Value & Sign & Value & Sign \\
\hline & $\mathrm{R}^{2}$ & 0.425 & 0 & 0.560 & 0 & 0.550 & 0 & 0.541 & 0 \\
\hline
\end{tabular}

${ }^{*} p<0.05 ; * * p<0.01 ; * * *<<0.001$

According to table 4, product innovation performance of enterprise is positive significant with its size. This result verifies the above argument. What' more, coefficients of centrality in tacit knowledge network are positive in model 2 and model 3, which indicates that an enterprise occuping a central position network has higher product innovation performance. However, centrality in explicit and tacit networks have no significant effect on product innovation. So, we can't judge in which network centrality is even more important for product innovation. Therefore, in the explicit and tacit knowledge networks of the mature cluster, the enterprise with higher centrality would be better for product innovation. In addition, the results show that structural holes in tacit knowledge network has positive effect on product innovation, also, it is negative correlation with the innovation in explicit knowledge network. The test results were not significant, so structural holes on the role of product innovation is uncertain. In general, in tacit knowledge transfer network of such a cluster, structure holes has inconspicuous impact on product innovation. 
Table 5 is the results of process innovation. Model 1 and 2 show that the size of an enterprise and centrality are positive correlated with process innovation performance. Consistent with the results in table 4, the results of model 3 in table 5 don't prove centrality of tacit knowledge network has bigger impact on process innovation. In short, the central position in the tacit and explicit knowledge networks is good for its process innovation within a traditional cluster. However, the difference of influention about explicit and tacit knowledge transfer network centrality on product innovation isn't clear. In addition, structural holes play both positive and negative roles on process innovation.

\section{Conclusion}

The strength of the relationship between enterprises and network structure have become important variables on the research of knowledge transfer and innovation within cluster. This study has two innovations on the technical level: Firstly, in view of the various relationships between enterprises in the cluster, we construct multiple networks included weak market relationship network and strong social relationship network. In the overall network structure level, we study structural correlation between relationship networks and knowledge transfer network. And we test what weak and strong relationship networks have effect on explicit and tacit knowledge transfer. Secondly, on the method of network construction, based on the descriptive advantages of the whole network, we construct the whole network, instead of egocentric and sampling network in the existing study.

This study found that:(1) The transfer of knowledge is common within the cluster, especially the explicit knowledge. There exist a wide range of ties between enterprises that are the main channel of knowledge transfer. (2) Strong relationship networks have bigger impact on transferring of tacit knowledge. Whatever weaker market relationship or stronger social relationship are the channel of explicit knowledge transfer within the cluster. But tacit knowledge transfer relays more on the strong relationships. (3) Enterprises with higher centrality have better performances both in product innovation and in process innovation. Compared to the centrality, the effect of structural holes on knowledge transfer is too weaker to be obvious.

Future studies can consider the whole properties of networks, such as cohesion, network range, coding of knowledge. Next, we can also consider the effect of out-degree and in-degree centrality of knowledge network on innovation. In addition, Further study on the network and the relationship between the enterprise innovation performance.

\section{Acknowledgement}

This research is financially supported by the SSF of Guangdong Province (No.2015A070704013) and Philosophy and social science project of Guangdong Province(GD15CYJ15);Guangdong key project of the integration of enterprises, universities and research institutes (NO.2009B090200062).

\section{References}

[1] Bathelt H., Malmberg A., Maskell P. Clusters and knowledge: Local buzz, global pipelines and the process of knowledge creation [J]. Progress in Huma Geography, 2004, 28, p31 56. 
[2] Szulanski, Gabrie 1. Exploring internal stickiness: impediments to the transfer of best practice within the firm [J]. Strategic Management Journal. 1996.

[3] Wang Wen-ping, Zhang Bing. Emergence characteristics of knowledge flow in knowledge networks under dynamic relationship strengths [J]. Journal Of Management Sciences In China, 2013, 16( 2) ,p1 11.

[4] Granovetter.The strength of weak tie [J].American Journal of Sociology, 1973, 78, p1360 1380.

[5] Uzzi, B. The sources and consequences of embeddedness for the economic performance of organizations: The network effect [J]. American Sociological Review, 1996.

[6] Wastyn A., Czarnitzki. Does professional knowledge management improve innovation performance at the firm level [D].Proceedings of the Imperial College London Business School Annual Conference, 2010.

[7] Cristóbal Casanueva, Ignacio Castro, José L.Galán.Informational networks and innovation in mature industrial clusters [J]. Journal of Business Research, 2013, 66,p603 613. 